\title{
Precision orientation herbicide spraying against weeds in plastic-mulched fields of spring hybrid millet
}

\author{
Meijun Guo', Xi-e Song', Jie Shen', Jianming Wang', Xiatong Zhao', Shaoguang Liu', Shuqi Dong', \\ Xiangyang Yuan ${ }^{1 *}$, Yinyuan Wen ${ }^{1}$, Pingyi Guo ${ }^{1 *}$, Xiaoxin $\mathrm{Shi}^{2}$, Yongfeng Shi ${ }^{2}$ \\ ${ }^{1}$ Key Laboratory of Crop Chemical Regulation and Chemical Weed Control, Agronomy College, Shanxi Agricultural University, Taigu 030801, \\ China, ${ }^{2}$ Taigu County Meteorological Bureau, Shanxi Province 030800, China
}

\section{A B S T R A C T}

Foxtail millet (Setaria italic [L.] P. Beauv.) is an important food and fodder crop that is cultivated worldwide. However, weeds severely inhibit the growth of spring foxtail millet, and no suitable herbicide or method is available for weed control in foxtail millet fields. Field experiments were conducted to evaluate the efficacy of various herbicides and their safety toward hybrid foxtail millet, that is, 'Zhangzagu $10^{\prime}$. The present study was conducted using seven herbicides applied by precision orientation spraying between plastic mulches in a foxtail millet field. All herbicide treatments exhibited no significant difference on foxtail millet shoot and root biomass. No difference in grain yield was observed among herbicide treatments, including MCPA (2-methyl-4-chlorophenoxyacetic acid), mesotrione, acetochlor, trifluralin, and pendimethalin, at the recommended dosage in field efficacy evaluation trial. For the same herbicide, the tendency of weed control increased with the increase in herbicide concentration. Following this finding, all herbicides applied at the highest dosage controlled weeds by $92.06 \%$ compared with the other treatments utilizing lower concentration. At the same concentration level, mesotrione controlled all weed populations was the highest observed among all herbicides, followed by prometryne and MCPA. Mesotrione controlled all weeds by at least $76.85 \%$, exhibiting the highest weed injury among the herbicides and satisfying the requirement for weed species control. Finally, comprehensive analyses showed that mesotrione at $0.8 \mathrm{~L} \mathrm{ha}^{-1}$, yielded the highest comprehensive evaluation value in foxtail millet field. Thus, this herbicide can be a good option in controlling weeds in foxtail millet field. This new model can aid in protecting hybrid 'Zhangzagu 10 ' foxtail millet seeds or seedlings against herbicide damage and is a good option in expanding the application range of herbicide in foxtail millet.

Keywords: Herbicide; Plastic mulching; Precision orientation spraying; Setaria italic; Spring hybrid millet

\section{INTRODUCTION}

Foxtail millet (Setaria italica [L.] P. Beauv.) is an important food and fodder crop in China (Wen et al., 2012). This plant has become increasingly popular to the local consumers due to its nutritional value. Additionally, the hybrid foxtail millet called Zhangzagu is popular because of its high resistance, yield, and nutritional value (Dong et al., 2014; Guo et al., 2016). However, foxtail millet production in China is limited by factors, including severe weed infestation (Guo et al., 2018). Weeds reduce crop yield, quality, and the market value of foxtail millet. Crop losses due to weed competition can reach as high as 55.56\% (Zhou et al., 2012).

At present, plastic mulching (mulched hole planting) can inhibit weed growth during early crop growth stage and increase crop yields (Li et al., 1999; Wang et al., 2009; Qin et al., 2014). Film mulching obstructs the photosynthesis of weeds under the membrane, which finally achieves the effect of weed control. However, plastic mulching also features notable negative effects. In plastic-mulched fields, weeds cause serious harm to spring hybrid millet between plastic mulches. Herbicides serve as an additional tool to control weeds combined with cultural practices (Barros et al., 2005; Zand et al., 2007; Baghestani et al., 2007); however, no information is available regarding the pre-emergence herbicide treatments applied to plastic-mulched Zhangzagu hybrid millet fields between plastic mulches. A large number of herbicides for other cereal crops are currently registered. However, foxtail millet is relatively sensitive to herbicides as it shares numerous characteristics with higher plants. The rational application of monosulfuron, monosulfuron plus propazine, 2,4-dichlorophenoxyacetic (2,4-D) and

${ }^{*}$ Corresponding authors:

Xiangyang Yuan and Pingyi Guo, Key Laboratory of Crop Chemical Regulation and Chemical Weed Control, Agronomy College, Shanxi Agricultural University, Taigu 030801, China. E-mail: pyguo126@126.com; yuanxiangyang200@163.com

Received: 12 May 2019; $\quad$ Accepted: 30 October 2019 
prometryn at the pre-emergence stage can control weeds effectively in foxtail millet fields but can easily cause phytotoxicity reaction (Tian et al., 2010).

Foxtail millet seedlings are small and feature slow growth at the first growth stages, and relatively poor competitive ability against weeds during the first few weeks of growth (Hanna et al., 2004; May et al., 2009; Reddy et al., 2014). Therefore, effective weed control is an essential component of spring hybrid millet production. Although chemical weed control is more efficient and economical compared to the manual weed control, there few suitable herbicides are registered for weed control in foxtail millet fields. It is reported that sthoxydim at the post-emergence stage can be used for grassy weed control in Zhangzagu (Xie et al. 2014), and the application of $22.5 \mathrm{~g}$ ai ha $\mathrm{ha}^{-1}$ of tribenuron-methyl at the post-emergence stage was found to be relatively safe for Zhangzagu 10 and did not affect its yield or grain quality (Ning et al. 2015). To avoid these problems, precision orientation spraying between plastic mulches can be used to substantially avoid direct contact between foxtail millet seeds or seedlings and herbicide, reduce phytotoxicity, and expand the application range of herbicides. In intermembrane precision orientation spraying, a precision herbicide is applied between plastic mulching and hole sowing in a foxtail millet field to significantly reduce the chances of direct contact between foxtail millet seed or seedlings and herbicide and to achieve precise chemical weed control with reduction dosage. Additionally, precision orientation spraying between plastic mulches will also reduce the environmental safety concerns in herbicides application by reducing the herbicide dosage used.

This study was therefore carried out to (1) evaluate the weed control efficacy of pre-emergence herbicides treatments applied to plastic-mulched hybrid millet between plastic mulches, (2) observe the effect of herbicides on hybrid millet production in terms of biomass, plant height and grain yield, (3) comprehensively evaluation of different herbicides on weed control efficiency and agronomic parameters of spring hybrid millet. Thus, the result is valuable as information for weed management in foxtail millet cultivation.

\section{MATERIALS AND METHODS}

\section{Field experiments}

Field experiments $\left(37^{\circ} 26^{\prime} \mathrm{N}, 112^{\circ} 32^{\prime} \mathrm{E}\right)$ were conducted at Shanxi Agricultural University, Taigu County, Shanxi Province, China, from May to October in 2015 and 2016. Tables 1 and 2 present the meteorological conditions and soil characteristics of the experimental site. The foxtail millet variety used in the experiment was a representative high-yield hybrid cultivar, that is, Zhangzagu 10, obtained from Zhangjiakou Academy of Agricultural Sciences of Hebei Province, China.

\section{Experimental design}

In the years of herbicide application (i.e. 2015 and 2016), experimental design was arranged in a randomized complete block design in triplicates. Millet seeds were sown in May by using $7.5 \mathrm{~kg}$ seeds ha ${ }^{-1}$, and mulched with plastic film with row spacing of 40 and $70 \mathrm{~cm}$, thereby yielding a density of 180000 plants ha ${ }^{-1}$ (field density recommended by the marketing company). Crops were harvested in October. Before planting, compound fertilizer $\left(750 \mathrm{~kg} \mathrm{ha}^{-1} ; \mathrm{N}: \mathrm{P}: \mathrm{K}\right.$ 18:18:18) was spread evenly and plowed into the soil layer.

Herbicide applications were prepared on 25 May 2015 and 26 May 2016. Table 3 shows the dosages of all herbicides. No herbicide was set as the control (CK). Herbicide treatments were applied by orientation spraying between plastic mulches using a handheld $\mathrm{CO}_{2}$ pressurized backpack boom sprayer equipped with flat-fan nozzles (3WBD-16, Pulandi Mechanical \& Electric Equipment, Shijiazhuang, China), and calibrated to deliver $450 \mathrm{~L} \mathrm{ha}^{-1}$ of spray solution at $0.7 \mathrm{MPa}$. To prevent the movement of herbicide in the treated areas, we left the outer $2 \mathrm{~m}$ of each plot unsprayed. Each experiment plot featured a dimension of $5 \mathrm{~m} \times 2.5 \mathrm{~m}$.

\section{Sampling techniques and observations}

Herbicide efficacy was assessed $30 \mathrm{~d}$ after treatment (DAT). Most competitive weed species in foxtail millet consist many dicotyledons weeds, such as thorn apple (Daturamonium L.), goosefoots (Chenopodium album L.), redroot amaranth (Amaranthus retroflexus), purslane (Portulaca oleracea L.), shepherdspurse herb (Capsella bursa-pastoris), copperleaf herb (Acalypha australis L.), abutilon (Abutilon theophrasti), and convolvulus pluricaulis (Convolvulus arvensis L.). In

\begin{tabular}{|c|c|c|c|c|c|c|c|c|c|c|}
\hline \multirow[t]{3}{*}{ Month } & \multicolumn{2}{|c|}{ Precipitation $(\mathrm{mm})$} & \multicolumn{4}{|c|}{ Temperature $\left({ }^{\circ} \mathrm{C}\right)$} & \multicolumn{2}{|c|}{$\geq 20^{\circ} \mathrm{C}$ accumulated temperature $\left({ }^{\circ} \mathrm{C}\right)$} & \multicolumn{2}{|c|}{ Shunshine hours (h) } \\
\hline & \multirow[t]{2}{*}{2015} & \multirow[t]{2}{*}{2016} & \multicolumn{2}{|c|}{2015} & \multicolumn{2}{|c|}{2016} & \multirow[t]{2}{*}{2015} & \multirow[t]{2}{*}{2016} & \multirow[t]{2}{*}{2015} & \multirow[t]{2}{*}{2016} \\
\hline & & & Min & Max & Min & Max & & & & \\
\hline 5 & 32.0 & 20.2 & 6.6 & 33.9 & 4.2 & 34.4 & 320.3 & 260.0 & 277.6 & 268.2 \\
\hline 6 & 15.5 & 61.9 & 11.0 & 35.4 & 11.2 & 36.5 & 649.4 & 531.8 & 231.6 & 286.7 \\
\hline 7 & 74.4 & 256.6 & 12.8 & 37.1 & 16.0 & 35.0 & 730.9 & 702.1 & 296.8 & 235.6 \\
\hline 8 & 67.6 & 137.5 & 12.3 & 32.6 & 10.8 & 34.3 & 661.9 & 629.1 & 269.2 & 244.0 \\
\hline 9 & 68.1 & 19.8 & 6.6 & 29.1 & 6.0 & 30.8 & 141.7 & 166.4 & 204.6 & 234.3 \\
\hline
\end{tabular}


addition, a small number of gramineous weeds include crab grass (Digitaria sanguinalis L.) and green bristlegrass (Setaria viridis $L$.). At each sampling plot, $0.1 \mathrm{~m}^{2}$ random quadrats per plot were used to monitor weed density, and measure foxtail millet plant height. Plants of each quadrat were uprooted manually. The collected foxtail millet plants were brought to the laboratory, and each group of plant sample was placed in a paper bag and oven-dried at $70^{\circ} \mathrm{C}$ for more than $72 \mathrm{~h}$ to determine biomass. At maturity, samples from each quadrant (excluding the ones on the borders) were collected to measure the yield components. Each sample was threshed using a panicle thresher, and grains were counted by a grain counter and weighed. To avoid border effects, we obtained samples for grain yield (adjusted to a moisture content of $14 \%$ ) determination by harvesting the central $5 \mathrm{~m}^{2}$ areas of each plot.

\section{Statistical analyses}

All statistical analyses were performed using Statistical Analysis System 8.0. (SAS Institute, Cary, North Carolina,

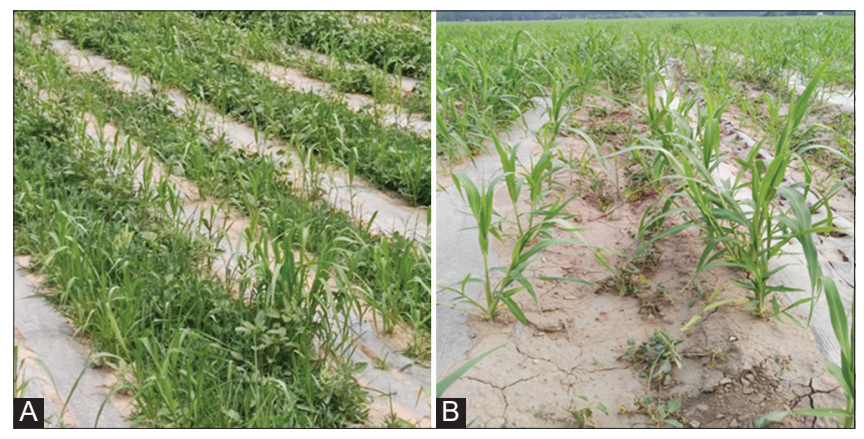

Fig 1. Effect of herbicides on weed control in foxtail millet field. (A) Representative photo of pre-experiment weed control. (B) Representative photo of after experiment weed control.

Table 2: Soil characteristics of the experimental fields

\begin{tabular}{lcc}
\hline Property & $\mathbf{2 0 1 5}$ & $\mathbf{2 0 1 6}$ \\
\hline $\mathrm{pH}$ & 8.12 & 7.85 \\
Total salt of soil, \% & 0.0827 & 0.1543 \\
Organic matter, $\mathrm{g} \mathrm{kg}^{-1}$ & 23.79 & 24.49 \\
Total N, $\mathrm{g} \mathrm{kg}^{-1}$ & 1.038 & 1.001 \\
Available N, mg kg-1 & 48.21 & 51.92 \\
Available $\mathrm{P}, \mathrm{mg} \mathrm{kg}^{-1}$ & 10.45 & 24.13 \\
Available K, mg kg-1 & 180.2 & 183.6 \\
\hline
\end{tabular}

USA). Data were presented as mean \pm standard error of the mean. Given the differences between years, data were presented separately for each year. Duncan's test was used to determine significant differences among treatments. $\mathrm{P}<0.05$ was used as the statistical significance threshold. In this study, the effects of different herbicide types and herbicide concentrations were analyzed by a $2 \times 2$ factorial random design. To eliminate the differences in growth index due to numerical value and range ability, this work quantitatively transformed the measurement indices via a five-point scoring method (Gao et al., 1983; Liu et al., 2015). Percent weed population reduction was calculated by the following formula: efficacy $(\%)=[$ (number of control weeds - weeds-number of treated weeds)/number of control weeds] $\times 100$. Efficacy data were arcsine-squareroot-transformed before statistical analysis.

\section{RESULTS}

Effect of pre-emergence herbicides on weed control In 2015 and 2016, the herbicides showed good performance in weed control when applied at the late emergence stage of foxtail millet in spring (Fig. 1). MCPA, mesotrione, and prometryne application exhibited substantial controlling effects on broad-leaved weeds than grasses. However, the application of acetochlor, metolachlor, trifluralin, and pendimethalin presented significant controlling effect on grasses compared with broad leaf weeds. Moreover, for all herbicides, weed control effect increased with the increase in dosage. At 30 DAT, broad leaf weed control was generally satisfactory for MCPA at T2; this result was more significant than those in other treatments $(92 \%)$ in 2015 and 2016 (Table 4). When trifluralin was applied in both years, difference was observed among the results. At T2, mesotrione manifested desirable weed control in $2015(92.59 \%)$ and 2016 (92.04\%). However, no difference was observed between broad leaf weeds under mesotrione and those under other treatments in 2016. Mesotrione also controlled weeds by at least $76.85 \%$, exhibiting the highest weed injury among the herbicides and satisfying the requirement for weed species control.

Table 3: List of herbicides for weed control in foxtail millet during 2015 and 2016

\begin{tabular}{|c|c|c|c|c|c|c|c|}
\hline \multirow[t]{2}{*}{ Herbicide type } & \multirow[t]{2}{*}{ Herbicides } & \multicolumn{5}{|c|}{ Application rates } & \multirow[t]{2}{*}{ Manufacturer } \\
\hline & & T1 & T2 & T3 & T4 & T5 & \\
\hline Phenoxy-carboxylic-acids & MCPA, kg ha-1 & 0.8 & 1.5 & 3 & 4.5 & 6 & Jiangsu Jiangu Chemical Inc. (Suqian, China) \\
\hline Triketones & Mesotrione, $\mathrm{L} \mathrm{ha}^{-1}$ & 0.8 & 1.5 & 3 & 4.5 & 6 & Shandong Vicome Greenland Chemical Inc. (Jinan, China) \\
\hline \multirow[t]{2}{*}{ Amides } & Acetochlor, $\mathrm{kg} \mathrm{ha}^{-1}$ & 0.8 & 1.5 & 2.3 & 3 & 4.5 & Shandong Vicome Greenland Chemical Inc. (Jinan, China) \\
\hline & Metolachlor, $\mathrm{kg} \mathrm{ha}^{-1}$ & 0.6 & 1.2 & 1.8 & 2.4 & 3.6 & Syngenta Crop Protection (Jiangsu, China) \\
\hline Trazines & Prometryne, $\mathrm{kg} \mathrm{ha}^{-1}$ & 0.4 & 0.8 & 1.1 & 1.5 & 2.3 & Shandong Vicome Greenland Chemical Inc. (Jinan, China) \\
\hline \multirow[t]{2}{*}{ Dinitroanilines } & Trifluralin, $\mathrm{L} \mathrm{ha}^{-1}$ & 0.6 & 1.1 & 1.7 & 2.3 & 3.4 & Shandong Lv Bang Crop Science (Jinan, China) \\
\hline & Pendimethalin, $\mathrm{kg} \mathrm{ha}^{-1}$ & 0.8 & 1.5 & 2.3 & 3 & 4.5 & Shandong Dong Tai Agro-chemical Inc.(Liaocheng, China) \\
\hline
\end{tabular}

$\mathrm{T} 1, \mathrm{~T} 2, \mathrm{~T} 3, \mathrm{~T} 4$, and T5 refer to herbicide application dosages, respectively; T2 refer to label recommendation according to the manufacturer 


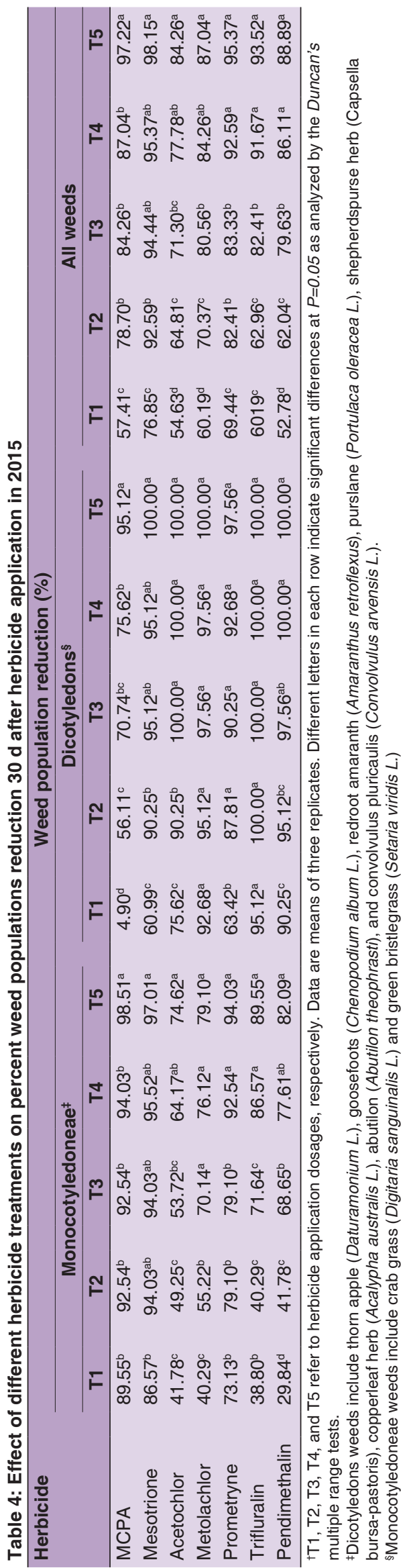



Emir. J. Food Agric • Vol 31 • Issue 11 • 2019 
Effect of different herbicide treatments on foxtail millet seedling growth

In this study, the plant height of Zhangzagu 10 varied between years and herbicide treatments (Tables 6 and 7, respectively). On one hand, mesotrione treatments significantly inhibited plant height between treatments in 2015. Plant height significantly decreased by $26.95 \%$ with the application of metolachlor at T5 in 2015. In 2015, plant height was significantly affected by MCPA, prometryne, trifluralin, pendimethalin treatments at T3, T4, and T5. On the other hand, the application of acetochlor significantly decreased plant height at T2, T3, T4, and T5 in 2015. However, acetochlor treatments significantly inhibited plant height at
T3, T4, and T5 in 2016. Compared with the control, plant height was significantly inhibited by MCPA, mesotrione, metolachlor, trifluralin, and pendimethalin application at T2, T3, T4, and T5 in 2016. Significant differences were also observed between treatments with prometryne application.

\section{Effect of different herbicide treatments on foxtail millet biomass}

In this study, herbicide treatments inhibited foxtail millet growth, as reflected by the reduced foxtail millet root and shoot biomasses (Figs. 2 and 3, respectively). Biomass yield was affected by herbicide treatments and years. In 2015, MCPA application at T3, T4, and T5 caused significant reductions in shoot biomass $(28.36 \%, 31.42 \%$ and $44.57 \%$,

Table 6: Effect of different herbicide treatments on seedling growth 30 DAHA in 2015

\begin{tabular}{|c|c|c|c|c|c|c|c|c|c|c|c|}
\hline \multirow[t]{2}{*}{ Herbicide } & \multicolumn{6}{|c|}{ Plant height $(\mathrm{cm})$} & \multicolumn{5}{|c|}{ Inhibition rate (\%) } \\
\hline & CK & T1 & T2 & T3 & T4 & T5 & T1 & T2 & T3 & T4 & T5 \\
\hline MCPA & $73.55 \pm 6.87^{a}$ & $66.25 \pm 2.25^{\mathrm{ab}}$ & $64.65 \pm 2.64^{\mathrm{ab}}$ & $60.75 \pm 1.84^{\mathrm{bc}}$ & $54.425 \pm 2.23^{c}$ & $53.07 \pm 1.94^{c}$ & 9.93 & 12.10 & 17.40 & 26.00 & 27.84 \\
\hline Mesotrione & & $59.97 \pm 3.67^{b}$ & $53.60 \pm 3.29^{b c}$ & $48.25 \pm 1.09^{b c}$ & $44.02 \pm 2.14^{c}$ & $42.50 \pm 2.61^{c}$ & 18.46 & 27.12 & 34.40 & 40.14 & 42.22 \\
\hline Acetochlor & & $60.62 \pm 4.34^{\mathrm{ab}}$ & $58.07 \pm 1.42^{b}$ & $56.27 \pm 5.89^{b}$ & $52.37 \pm 3.21^{b}$ & $48.12 \pm 3.11^{b}$ & 17.57 & 21.04 & 23.49 & 28.79 & 34.57 \\
\hline Metolachlor & & $62.37 \pm 8.07^{\mathrm{ab}}$ & $61.82 \pm 4.09^{\mathrm{ab}}$ & $60.00 \pm 8.07^{\mathrm{ab}}$ & $57.77 \pm 4.61^{\mathrm{ab}}$ & $53.72 \pm 4.60^{\mathrm{b}}$ & 15.19 & 15.94 & 18.42 & 21.45 & 26.95 \\
\hline Prometryne & & $69.87 \pm 2.08^{a}$ & $64.52 \pm 6.74^{\mathrm{ab}}$ & $58.35 \pm 6.69^{b c}$ & $51.52 \pm 4.78^{\mathrm{cd}}$ & $43.75 \pm 1.52^{\mathrm{d}}$ & 5.00 & 12.27 & 20.67 & 29.95 & 40.52 \\
\hline Trifluralin & & $65.00 \pm 7.00^{\mathrm{ab}}$ & $57.97 \pm 7.03^{\mathrm{abc}}$ & $53.17 \pm 3.56^{\mathrm{bc}}$ & $52.90 \pm 4.72^{\mathrm{bc}}$ & $42.60 \pm 4.80^{c}$ & 11.62 & 21.18 & 27.70 & 28.08 & 42.08 \\
\hline Pendimethalin & & $70.12 \pm 11.05^{a}$ & $60.82 \pm 6.56^{a}$ & $43.57 \pm 1.45^{b}$ & $39.90 \pm 2.84^{b}$ & $39.87 \pm 2.30^{b}$ & 4.66 & 17.30 & 40.75 & 45.75 & 45.79 \\
\hline
\end{tabular}

T1, T2, T3, T4, and T5 refer to herbicide application dosages, respectively. CK refers to the "no herbicide" treatment (control). Data are means of three replicates. Different letters in each row indicate significant differences at $P=0.05$ as analyzed by the Duncan's multiple range tests

Table 7: Effect of different herbicide treatments on seedling growth 30 DAHA in 2016

\begin{tabular}{|c|c|c|c|c|c|c|c|c|c|c|c|}
\hline \multirow[t]{2}{*}{ Herbicide } & \multicolumn{6}{|c|}{ Plant height (cm) } & \multicolumn{5}{|c|}{ Inhibition rate (\%) } \\
\hline & CK & T1 & T2 & T3 & T4 & T5 & T1 & T2 & T3 & T4 & T5 \\
\hline MCPA & $70.60 \pm 4.24^{a}$ & $59.70 \pm 5.17^{\mathrm{ab}}$ & $51.24 \pm 5.51^{b c}$ & $49.46 \pm 2.09^{b c}$ & $48.60 \pm 6.30^{b c}$ & $43.56 \pm 2.00^{c}$ & 15.44 & 27.42 & 29.94 & 31.16 & 38.3 \\
\hline Mesotrione & & $58.62 \pm 6.59^{\mathrm{ab}}$ & $52.74 \pm 5.75^{\mathrm{bc}}$ & $51.34 \pm 3.99^{b c}$ & $48.10 \pm 2.28^{b c}$ & $43.80 \pm 2.32^{c}$ & 16.97 & 25.30 & 27.28 & 31.87 & 37.96 \\
\hline Acetochlor & & $62.36 \pm 6.26^{\mathrm{ab}}$ & $61.98 \pm 5.19^{\mathrm{ab}}$ & $47.38 \pm 6.45^{b}$ & $46.08 \pm 6.87^{b}$ & $45.96 \pm 1.68^{b}$ & 11.67 & 12.21 & 32.89 & 34.73 & 34.90 \\
\hline Metolachlor & & $65.46 \pm 3.87^{\mathrm{a}}$ & $46.24 \pm 0.88^{b}$ & $45.64 \pm 3.25^{b}$ & $45.24 \pm 1.68^{b}$ & $42.86 \pm 2.54^{b}$ & 7.28 & 34.50 & 35.35 & 35.92 & 39.29 \\
\hline Prometryne & & $52.02 \pm 7.15^{b}$ & $49.50 \pm 1.10^{b}$ & $46.08 \pm 2.50^{b}$ & $44.56 \pm 0.66^{b}$ & $40.84 \pm 2.20^{b}$ & 26.32 & 29.89 & 34.73 & 36.88 & 42.15 \\
\hline Trifluralin & & $62.62 \pm 2.03^{\mathrm{ab}}$ & $56.12 \pm 5.04^{\mathrm{bc}}$ & $54.96 \pm 5.47^{\mathrm{bc}}$ & $45.30 \pm 1.23^{c d}$ & $42.36 \pm 1.10^{d}$ & 11.30 & 20.51 & 22.15 & 35.84 & 40.00 \\
\hline Pendimethalin & & $62.60 \pm 6.96^{\mathrm{ab}}$ & $53.22 \pm 5.46^{\mathrm{bc}}$ & $48.88 \pm 4.39^{b c}$ & $46.96 \pm 2.85^{c}$ & $44.24 \pm 1.37^{c}$ & 11.33 & 24.62 & 30.76 & 33.48 & 37.34 \\
\hline
\end{tabular}

T1, T2, T3, T4, and T5 refer to herbicide application dosages, respectively. CK refers to the "no herbicide" treatment (control). Data are means of three replicates. Different letters in each row indicate significant differences at $P=0.05$ as analyzed by the Duncan's multiple range tests

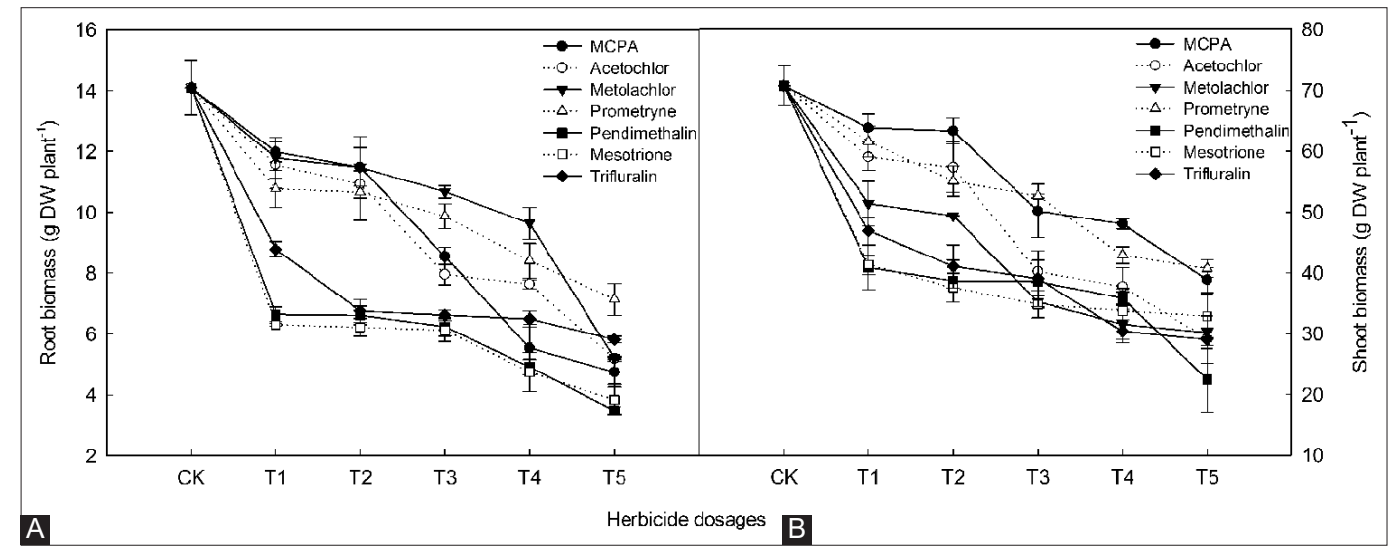

Fig 2. (A and B) Effect of herbicides on foxtail millet biomass in 2015. T1, T2, T3, T4, and T5 refer to herbicide application dosages, respectively; CK refers to the "no herbicide" treatment (control). Values represent means; vertical bars represent the standard deviation of three separate experiments. The abscissa in the figure represents the dosage of herbicides. 
respectively) compared with the control. However, no significant difference was observed among treatments with MCPA application in 2016. Compared with the control, shoot biomass was significantly inhibited with mesotrione, acetochlor, metolachlor, prometryne, trifluralin, and pendimethalin application. In 2016, treatments with T2, T3, $\mathrm{T} 4$, and $\mathrm{T} 5$ resulted in significant decrease in shoot biomass between mesotrione $(23.73 \%, 32.54 \%, 48.12 \%$, and $51.19 \%$, respectively) and acetochlor $(32.93 \%, 36.08 \%, 58.78 \%$, and $60.68 \%$, respectively). However, a significant difference was observed among treatments with MCPA, metolachlor, prometryne, trifluralin, and pendimethalin. Additionally, root biomass was negatively affected by MCPA, mesotrione, acetochlor, metolachlor, prometryne, trifluralin, and pendimethalin, in which significant differences were found among treatments compared with control in 2015 and 2016.

\section{Effect of different herbicide treatments on foxtail millet yield}

Reduction in biomass and plant height reduces yield components, thereby also causing a reduction in grain yield. In this study, increasing herbicide dosages negatively affected yield in both years. However, no significant differences were observed between treatments with acetochlor application in 2015 and mesotrione in 2016 (Tables 8 and 9, respectively). On the other hand, increasing MCPA dosages significantly

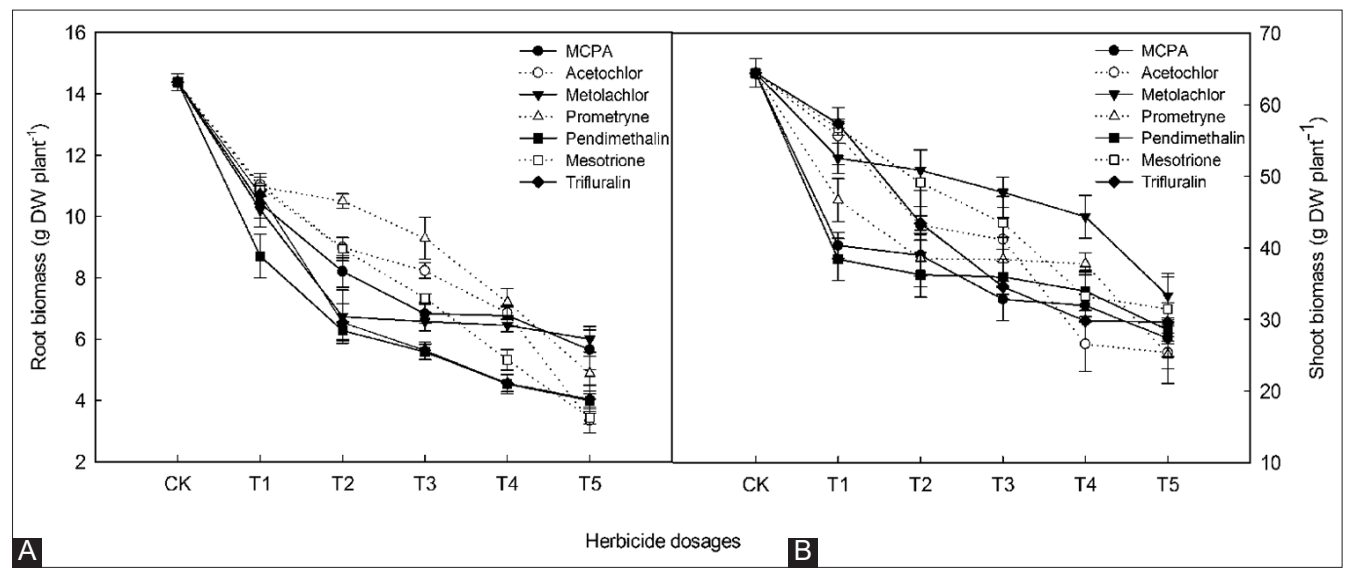

Fig 3. (A and B) Effect of herbicides on foxtail millet biomass in 2016. T1, T2, T3, T4, and T5 refer to herbicide application dosages, respectively; CK refers to the "no herbicide" treatment (control). Values represent means; vertical bars represent the standard deviation of three separate experiments. The abscissa in the figure represents the dosage of herbicides.

Table 8: Effect of different herbicide treatments on grain yield in 2015

\begin{tabular}{lcccccc}
\hline Herbicide & \multicolumn{5}{c}{ Grain Yield $\left.(\mathbf{k g ~ h a})^{-1}\right)$} \\
\cline { 2 - 7 } & CK & T1 & T2 & T3 & T4 & T5 \\
\hline MCPA & $7789.26 \pm 341.39^{\mathrm{a}}$ & $7694.66 \pm 371.04^{\mathrm{ab}}$ & $7484.45 \pm 422.60^{\mathrm{ab}}$ & $7326.53 \pm 72.68^{\mathrm{ab}}$ & $7043.10 \pm 7.17^{\mathrm{ab}}$ & $6750.40 \pm 218.06^{\mathrm{b}}$ \\
Mesotrione & & $7285.15 \pm 293.34^{\mathrm{ab}}$ & $7275.86 \pm 209.72^{\mathrm{ab}}$ & $6712.08 \pm 360.83^{\mathrm{ab}}$ & $6424.63 \pm 7.43^{\mathrm{b}}$ & $6231.77 \pm 451.59^{\mathrm{b}}$ \\
Acetochlor & & $7606.78 \pm 270.28^{\mathrm{a}}$ & $7573.82 \pm 80.36^{\mathrm{a}}$ & $7524.92 \pm 264.86^{\mathrm{a}}$ & $7453.87 \pm 299.52^{\mathrm{a}}$ & $6805.87 \pm 315.81^{\mathrm{a}}$ \\
Metolachlor & & $7681.37 \pm 141.92^{\mathrm{a}}$ & $7290.64 \pm 264.13^{\mathrm{ab}}$ & $7222.29 \pm 285.12^{\mathrm{ab}}$ & $6864.66 \pm 42.19^{\mathrm{b}}$ & $5110.65 \pm 174.62^{\mathrm{c}}$ \\
Prometryne & & $7664.15 \pm 139.54^{\mathrm{ab}}$ & $6939.72 \pm 152.95^{\mathrm{bc}}$ & $6811.56 \pm 211.88^{\mathrm{c}}$ & $5473.17 \pm 195.55^{\mathrm{d}}$ & $5137.00 \pm 387.54^{\mathrm{d}}$ \\
Trifluralin & & $7653.16 \pm 284.74^{\mathrm{a}}$ & $7189.95 \pm 142.33^{\mathrm{ab}}$ & $6964.74 \pm 543.92^{\mathrm{ab}}$ & $6754.19 \pm 68.92^{\mathrm{b}}$ & $4846.39 \pm 121.06^{\mathrm{c}}$ \\
Pendimethalin & & $7555.51 \pm 214.09^{\mathrm{a}}$ & $7506.08 \pm 189.95^{\mathrm{a}}$ & $6337.36 \pm 255.28^{\mathrm{b}}$ & $5932.72 \pm 169.67^{\mathrm{bc}}$ & $5434.11 \pm 254.93^{\mathrm{c}}$ \\
\hline
\end{tabular}

T1, T2, T3, T4, and T5 refer to herbicide application dosages, respectively. CK refers to the "no herbicide" treatment (control). Data are means of three replicates. Different letters in each row indicate significant differences at $P=0.05$ as analyzed by the Duncan's multiple range tests

Table 9: Effect of different herbicide treatments on grain yield in 2016

\begin{tabular}{lcccccc} 
Herbicide & \multicolumn{5}{c}{ Grain yield $\left.(\mathbf{k g ~ h a})^{-1}\right)$} \\
\cline { 2 - 7 } & CK & T1 & T2 & T3 & T4 \\
\hline MCPA & $7780.75 \pm 204.06^{\mathrm{a}}$ & $7513.54 \pm 167.79^{\mathrm{ab}}$ & $7472.41 \pm 221.08^{\mathrm{ab}}$ & $7447.34 \pm 354.88^{\mathrm{ab}}$ & $7270.89 \pm 536.69^{\mathrm{ab}}$ & $6615.05 \pm 255.16^{\mathrm{b}}$ \\
Mesotrione & $7453.89 \pm 205.77^{\mathrm{a}}$ & $7453.35 \pm 323.85^{\mathrm{a}}$ & $7373.18 \pm 191.71^{\mathrm{a}}$ & $7185.42 \pm 322.85^{\mathrm{a}}$ & $7056.79 \pm 56.74^{\mathrm{a}}$ \\
Acetochlor & $7047.87 \pm 174.34^{\mathrm{ab}}$ & $7003.25 \pm 168.05^{\mathrm{ab}}$ & $6746.50 \pm 381.33^{\mathrm{b}}$ & $6390.15 \pm 378.79^{\mathrm{bc}}$ & $5842.03 \pm 74.94^{\mathrm{c}}$ \\
Metolachlor & $7010.76 \pm 96.76^{\mathrm{b}}$ & $6589.59 \pm 308.42^{\mathrm{b}}$ & $6524.93 \pm 148.65^{\mathrm{b}}$ & $6342.05 \pm 146.54^{\mathrm{b}}$ & $5412.57 \pm 431.71^{\mathrm{c}}$ \\
Prometryne & $7691.55 \pm 181.09^{\mathrm{a}}$ & $7014.51 \pm 398.87^{\mathrm{ab}}$ & $6748.73 \pm 680.15^{\mathrm{ab}}$ & $6100.50 \pm 678.98^{\mathrm{b}}$ & $5857.90 \pm 370.48^{\mathrm{b}}$ \\
Trifluralin & $7705.62 \pm 71.03^{\mathrm{a}}$ & $7691.18 \pm 137.41^{\mathrm{a}}$ & $7573.80 \pm 146.75^{\mathrm{ab}}$ & $7290.40 \pm 701.75^{\mathrm{ab}}$ & $6609.39 \pm 176.10^{\mathrm{b}}$ \\
Pendimethalin & $7577.51 \pm 28.84^{\mathrm{ab}}$ & $7430.38 \pm 213.53^{\mathrm{ab}}$ & $6947.92 \pm 171.10^{\mathrm{bc}}$ & $6635.18 \pm 297.62^{\mathrm{c}}$ & $6586.88 \pm 87.14^{\mathrm{c}}$ \\
\hline
\end{tabular}

T1, T2, T3, T4, and T5 refer to herbicide application dosages, respectively. CK refers to the "no herbicide" treatment (control). Data are means of three replicates. Different letters in each row indicate significant differences at $P=0.05$ as analyzed by the Duncan's multiple range tests 
decreased the yield by $13.34 \%$ and $14.98 \%$ at T5 in 2015 and 2016, respectively. In 2015, the yield was significantly affected by mesotrione, metolachlor, and trifluralin treatments at T4 and T5. However, the yield significantly decreased by $15.04 \%$ with trifluralin application at $\mathrm{T} 5$ in 2016. Furthermore, significant differences were observed among the treatments with mesotrione application in 2016. Prometryne application significantly decreased yields at T2, T3, T4, and T5 in 2015. Significant differences were observed at T4 and T5 in 2016. Additionally, increasing pendimethalin dosages significantly decreased yields at $\mathrm{T} 3$, $\mathrm{T} 4$, and $\mathrm{T} 5$ in both years. A similar response was observed for yield exposed to acetochlor in 2016, which showed significant difference at $\mathrm{T} 3, \mathrm{~T} 4$, and $\mathrm{T} 5$.

\section{Comprehensive evaluation of different herbicides on weed control efficiency and grain yield}

As shown in Table 10, two years' worth of data remarkably differed but consistently followed the trend. For the same herbicide, the tendency of weed control increased with the increase in herbicide concentration, and this result significantly differed from those of other treatments. Following this finding, all herbicides applied at the highest dosage controlled weeds by $92.06 \%$ compared with the other treatments utilizing lower concentration. At the same concentration level, mesotrione controlled all weed populations was the highest observed among all herbicides, followed by prometryne and MCPA.

In this study, on the basis of the variation coefficient of each index in weight analysis, we comprehensively evaluated weed control effect, plant height, shoot biomass, root biomass and yield under herbicide processing. In terms of weight coefficient, the weight coefficient of yield was the lowest, and the weight of root biomass was the highest, indicating that herbicides had an inhibitory effect on plant roots. Comprehensive evaluation showed the highest value with C1, followed by G1 and D1. These results indicated that these treatments feature good weed control and effectively increase production in the foxtail millet field (Table 11). These results agree with weed control results (Table 10).

\section{DISCUSSION}

The same weed species were observed in 2015 and 2016, and the weed community was relatively stable in experimental plots. Barros et al. (2005) reported the different susceptibilities of weed species to herbicides. On one hand, MCPA, mesotrione, and prometryne are effective on several broad-leaf weeds; acetochlor, metolachlor, trifluralin, and pendimethalin work effectively on specific grass types. On the other hand, different herbicides or dosages cause different effects on crop yields (Ji et al., 2007;
Table 10: ANOVA table with F-values for different herbicides on the weed control

\begin{tabular}{lcc}
\hline Year & 2015 & 2016 \\
\hline Treatment & $61.64^{\mathrm{e}}$ & \\
T1 & $73.41^{\mathrm{d}}$ & $60.09^{\mathrm{e}}$ \\
T2 & $82.28^{\mathrm{c}}$ & $72.82^{\mathrm{d}}$ \\
T3 & $87.83^{\mathrm{b}}$ & $80.79^{\mathrm{c}}$ \\
T4 & $92.06^{\mathrm{a}}$ & $88.75^{\mathrm{b}}$ \\
T5 & $66.81^{\text {** }}$ & $92.92^{\mathrm{a}}$ \\
F-value & & $43.12^{\text {** }}$ \\
Herbicide & $80.93^{\mathrm{bc}}$ & \\
MCPA & $91.48^{\mathrm{a}}$ & $80.36^{\mathrm{bc}}$ \\
Mesotrione & $70.56^{\mathrm{e}}$ & $91.15^{\mathrm{a}}$ \\
Acetochlor & $76.48^{\mathrm{d}}$ & $76.82^{\text {cd }}$ \\
Metolachlor & $84.63^{\mathrm{b}}$ & $72.75^{\mathrm{d}}$ \\
Prometryne & $78.15^{\mathrm{cd}}$ & $84.43^{\mathrm{b}}$ \\
Trifluralin & $73.89^{\mathrm{de}}$ & $76.64^{\text {cd }}$ \\
Pendimethalin & $18.90^{\star *}$ & $75.58^{\text {cd }}$ \\
F-value & & $9.56^{\text {** }}$ \\
\hline
\end{tabular}

${ }^{* *}$ Significant differences at $1 \%$ levels.

Different letters in each row indicate significant differences at $P=0.05$.

$\mathrm{T} 1, \mathrm{~T} 2, \mathrm{~T} 3, \mathrm{~T} 4$, and T5 refer to herbicide application dosages, respectively

Opeña et al., 2014; Hausman et al., 2016). Our results showed that different herbicide treatments exerted varying effects on weed control, and the reduction in percent weed populations increased with the consistent improvement of herbicides in the appropriate range (Tables 4 and 5). All herbicides, including MCPA, mesotrione, and prometryne, were applied with the highest dose and control broad-leaf weeds by more than $95 \%$ compared with the other treatments. In accordance with our results, on the basis of different studies on several crops and under different environmental conditions, Zhang et al. (2000) observed that herbicide efficiencies in controlling weeds differ according to different herbicide doses.

The safety of herbicides on crops can be assessed by measuring grain yield, quality, and agronomic traits (Rieger et al., 2008; Robinson et al.; 2013; Yuan et al., 2013; Ning et al., 2015). Wang (2009) reported that the yield of soybean fields with applied herbicides was higher than that of the control, but the high concentration of metolachlor and fomesafen can inhibit plant height and fresh weight of soybean. As a result, shoot biomass, root biomass, and plant height significantly reduced, thereby decreasing grain yield. These results were consistent with those obtained by Robinson et al. (2013), who reported that yield is reduced by decreasing agronomic characteristics after exposure to herbicides. The results were also consistent with findings of Tian et al. (2010), who reported that monosulfuron, monosulfuron plus propazine, 2,4-D and prometryn caused damage in foxtail millet, and this result may due to reduced root activity.

In the field, herbicides exerted different influences on yield and weed control efficacy in two years, owing to the 


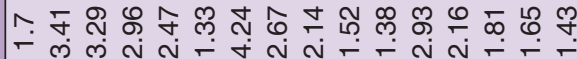

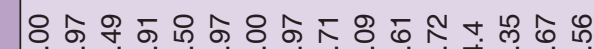
Oें 户े

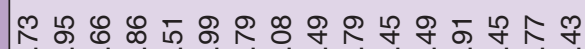

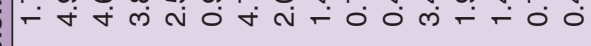

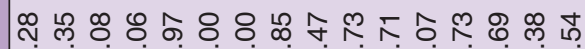

-m n n

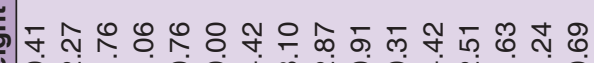

年

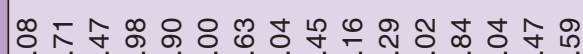

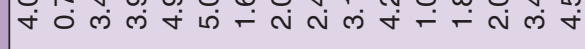



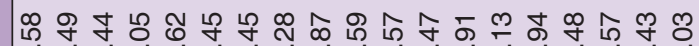



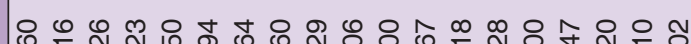

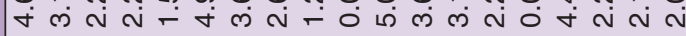

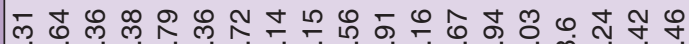
๓

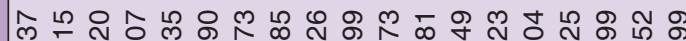
n n十

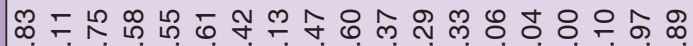

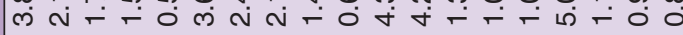

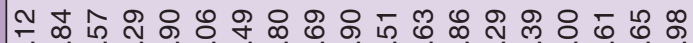

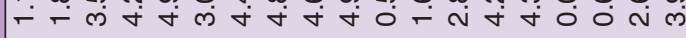

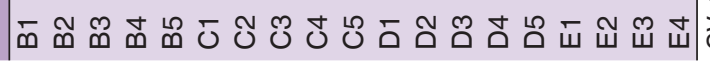

differences caused by field environment imbalances, such as soil fertility and irrigation conditions. However, the different herbicide treatments on foxtail millet followed a consistent trend. Following this result, the mesotrione, when applied at the highest dosage controlled weeds by $>$ 90\% compared with other treatments. A decline in foxtail millet grain yield was obtained after herbicide treatments (Tables 8 and 9), and foxtail millet was damaged by high herbicide dosage. In general, in the suitable concentration range, herbicide at high dosage provides good weed control, and significantly increases yield. However, in the present study, the seven herbicides caused effect on yield at high concentration than at medium concentration. In accordance with our results, Wu et al. (2001) demonstrated that no difference was observed on grain yield at low 'YuBao' (atrazine+rimsulfuron) dosage applied in a corn field; weed control significantly increased at high doses, whereas the yield was lower than that under the intermediate dose. However, in the field efficacy evaluation trial, we found no difference in grain yield under various herbicide treatments at the recommended dosages of MCPA, mesotrione, acetochlor, trifluralin, and pendimethalin. Yield reduction also differed between years and herbicide varieties. Differences in yield reduction may be attributed to herbicide-tolerant varieties and climatic conditions during the two-year study period.

Positive effects were also observed between weed control and grain yield of foxtail millet. The findings from the field showed that the yield of below-labeled doses of herbicides were higher than that of high herbicide dosage. Although screening herbicides causes no substantial phytotoxicity on foxtail millet seedling, herbicides remain a stress for crops and can indirectly affect soil properties, nutrition transfer and absorption of plant root, especially when exceeding a certain concentration, thus affecting foxtail millet yield. On the other hand, the misuse or overdose of herbicide can cause phytotoxicity, which can reduce crop yield. This study also showed that the double dose of herbicides can cause severe crop reduction. This result was consistent with the observations of Zhang et al. (2000), Boström and Fogelfors (2002), and Barros et al. (2005), who observed that maximum weed control is not always necessary to achieve the yield potential of the crop. In addition, the utilization of the below-labeled dosages of herbicides can be an effective way of reducing herbicide inputs in field crops while maintaining satisfactory weed control.

High efficiency, yield and safety are the main objectives of herbicide application. Seven herbicides were selected by field trials as the best candidates for soil treatments. Precision orientation spraying between plastic mulches can substantially avoid direct contact between foxtail millet 
seeds or seedlings and herbicides, reduce phytotoxicity, and expand the application range of herbicides. The results indicated that all herbicides performed well in these aspects.

\section{CONCLUSION}

In conclusion, the recommended dosage of herbicides is relatively safe for a hybrid variety of foxtail millet ('Zhangzagu 10') under the growing conditions and precision orientation spraying between plastic mulches. At this dosage, herbicides exhibited good weed control and high grain yield. Finally, results showed that mesotrione, at a highest concentration of $0.8 \mathrm{~L} \mathrm{ha}^{-1}$, can provide efficient and safe benefits on foxtail millet.

\section{ACKNOWLEDGEMENTS}

This work was supported by The system of National Modern Agriculture Technology (CARS-06-13.5-A28), the Scientific and Technological Project in Shanxi Province, China (20150311016-2), the National Natural Science Foundation of China (31301269), the National Science and Technology Support Plan of China (2014BAD07B01), the Key Research and Development General Project in Shanxi Province, China (201603D221003-2), the Key Scientific and Technological Project of Shanxi Province (2015-TN-09), and the Program for the Top Young Innovative Talents of Shanxi Agricultural University (TYIT201406).

\section{Authors' contribution}

The authors gratefully acknowledge the help of all authors of this paper. Meijun Guo was responsible for preparing the final version of manuscript. Pingyi Guo helped conceive the experiments and was the project director. Yuan Xiangyang and Jianming Wang were involved in review the language of the manuscript. Xi-e Song and Yinyuan Wen helped analysis and interpretation of data. Jie Shen and Shuqi Dong provided us with reagents, material and analysis tool. Xiatong Zhao and Shaoguang Liu were involved in conducing experiments. Xiaoxin Shi and Yongfeng Shi were involved in literature collection. All authors were responsible for analysis and interpretation of obtained results.

\section{REFERENCES}

Baghestani, M. A., E. Zand, S. Soufizadeh, A. Eskandari, R. PourAzar, M. Veysi and N. Nassirzadeh. 2007. Efficacy evaluation of some dual purpose herbicide to control weeds in maize (Zea mays L.). Crop Prot. 26: 936-942.

Barros, J. F. C., G. Basch and M. de Carvalho. 2005. Effect of reduced doses of a post-emergence graminicide mixture to control Lolium rigidum $\mathrm{G}$. In winter wheat under direct drilling in Mediterranean environment. Crop Prot. 24: 880-887.

Boström, U. and H. Fogelfors. 2002. Response of weeds and crop yield to herbicide dose decision-support guidelines. Weed Sci. 50: 186-195.

Dong, B. D., M. Y. Liu, J. W. Jiang, C. H. Shi, X. M. Wang, Y. Z. Qiao, Y. Y. Liu, Z. H. Zhao, D. X. Li and F. Y. Si. 2014. Growth, grain yield, and water use efficiency of rain-fed spring hybrid millet (Setaria italica) in plastic-mulched and unmulched fields. Agric. Water Manag. 143: 93-101.

Gao, J. Y., C. J. Ardrew and K. Pomeroy. 1983. Interactions among flooding, freezing and ice encasement in winter wheat. Plant Physiol. 72: 303-307.

Guo, D. X., P. Y. Guo, X. Y. Yuan and H. J. Yang. 2016. Effects of different cultivation methods on soil temperature, soil moisture and water use efficiency of millet. J. Soil Water Conserv. 30: 159-165.

Guo, M. J., Y. G. Wang, S. Q. Dong, Y. Y. Wen, X. E. Song and P. Y. Guo. 2018. Photochemical changes and oxidative damage in four foxtail millet varieties following exposure to sethoxydim. Photosynthetica. 56: 820-831.

Hanna, W. W., D. D. Baltensperger and A. Seetharam. 2004. Pearl millet and other millets. Agron. Monogr. 45: 537e-560.

Hausman, E. H., P. J. Tranel, D. E. Riechers and A. G. Hager. 2016. Responses of a waterhemp (Amaranthus tuberculatus) population resistant to HPPD-inhibiting herbicides to foliarapplied herbicides. Weed Technol. 30: 106-115.

Ji, G. S., R. H. Du, S. L. Hou, R. H. Cheng, X. Y. Wang and X. P. Zhao. 2007. Genetics, development, and application of cytoplasmic herbicide resistance in foxtail millet. Agric. Sci. China. 6: 779-785.

Li, F. M., A. H. Guo and H. Wei. 1999. Effect of clear plastic film mulch on yield of spring wheat. Field Crops Res. 63: 79-86.

Liu, H., P. Mu, G. Q. Zhao and T. Hao. 2015. Effect of two tested herbicides on the yield of oat, weed control and safety of succeeding crops. Acta Agrestia Sin. 23: 187-193.

May, W. E., E. N. Johnson, D. J. Ulrich, C. B. Holzapfel and G. P. Lafond. 2009. Tolerance of foxtail millet to combinations of bromoxynil, clopyralid, fluroxypyr, and MCPA. Weed Technol. 23: 94-98.

Ning, N., X. X. Yuan, S. Q. Dong, Y. Y. Wen, Z. P. Gao, M. J. Guo and P. Y. Guo. 2015. Grain yield and quality of foxtail millet (Setaria italica L.) In response to tribenuron-methyl. PLoS One. 10: e0142557.

Opeña, J. L., J. R. Quilty, T. Q. Correa and B. S. Chauhan. 2014. Weed population dynamics, herbicide efficacies, and crop performance in a sprinkler-irrigated maize-rice cropping system. Field Crops Res. 167: 119-130.

Qin, S. H., J. L. Zhang, H. L. Dai, D. Wang and D. M. Li. 2014. Effect of ridge-furrow and plastic-mulching planting patterns on yield formation and water movement of potato in a semi-arid area. Agric. Water Manag. 131: 87-94.

Reddy, S. S., P. W. Stahlman, P. W. Geier, L. D. Charvat, R. G. Wilson and M. J. Moechnig. 2014. Tolerance of foxtail, proso and pearl millets to saflufenacil. Crop Prot. 57: 57-62.

Rieger, S., W. Richner, B. Streit, E. Frossard and M. Liedgens. 2008. Growth, yield, and yield components of winter wheat and the effects of tillage intensity, preceding crops, and $\mathrm{N}$ fertilization. Eur. J. Agron. 28: 405-411.

Robinson, A. P., D. M. Simpson and W. G. Johnson. 2013. Response of glyphosate-tolerant soybean yield components to dicamba exposure. Weed Sci. 61: 526-536.

Tian, B. H., J. G. Wang, Y. J. Li and L. X. Zhang. 2010. Study on selection of suitable herbicides for hybrid millet. J. Hebei Agric. 
Sci. 14: 46-47.

Wang, H. W. 2009. Influence of different combinations on quality and yield of soybean variety Hefeng 39. Chin. Agric. Sci. Bull. 25: 182-184.

Wang, Y. J., Z. K. Xie, S. S. Malhi, C. L. Vera, Y. B. Zhang and J. N. Wang. 2009. Effects of rainfall harvesting and mulching technologies on water use efficiency and crop yield in the semiarid loess Plateau, China. Agric. Water Manag. 96: 374-382.

Wen, X. X., D. Zhang, Y. Liao, Z. Jia and S. Ji. 2012. Effect of watercollecting and retaining techniques on photosynthetic rates, yield, and water use efficiency of millet grown in a semiarid region. J. Int. Agric. 11: 1119-1128.

Wu, M. G., M. J. Fu, Y. Z. Han, H. F. Liu and Y. H. Quan. 2001. Effects of weed control "Yubao" herbicide in maize. J. Agric. Sci. Yanbian Univ. 23: 40-43.

Xie, L. L., P. Y. Guo, X. Y. Yuan, M. E. Nie, J. Guo, N. Ning, M. J. Guo and Z. P. Gao. 2014. Effect of sethoxydim on physiological characteristic of hybrid millet Zhangzagu 5 seedling. J. Shanxi Agric. Sci. 42:223-226.

Yuan, X. Y., P. Y. Guo, X. Qi, N. Ning, H. Wang, H. F. Wang, X. Wang and Y. J. Yang. 2013. Safety of herbicide sigma broad on radix isatidis (Isatis indigotica Fort.) seedlings and their photosynthetic physiological responses. Pestic. Biochem. Physiol. 106: 45-50.

Zand, E., M. A. Baghestani, S. Soufizadeh, R. PourAzar, M. Veysi, N. Bagherani, A. Barjasteh, M. M. Khayami and N. Nezamabadi. 2007. Broadleaved weed control in winter wheat (TriticumaestivumL.) with post-emergence herbicide in Iran. Crop Prot. 26: 746-752.

Zhang, J., S. E. Weaver and A. S. Hamill. 2000. Risks and reliability of using herbicides at below-labeled doses. Weed Technol. 14: 106-115.

Zhou, H. Z., H. X. Liu, K. Y. Bo, Y. F. Song, H. Y. Jia, P. Lv, X. Y. Wang, E. Q. Liu and S. L. Hou. 2012. Study on prediction model of millet yield loss caused by weeds in summer season millet field. J. Agric. 2: 12-15. 